\title{
Author Correction: The impact of conflict-driven cropland abandonment on food insecurity in South Sudan revealed using satellite remote sensing
}

Victor Mackenhauer Olsen (D), Rasmus Fensholt (D), Pontus Olofsson (iD, Rogerio Bonifacio, Van Butsic (D), Daniel Druce (D), Deepak Ray (iD) and Alexander V. Prishchepov (D)

Correction to: Nature Food https://doi.org/10.1038/s43016-021-00417-3, published online 16 December 2021.

In the version of this article initially published, there was an error in Table 1. In the third column, the relative \% decline of cropland in the 5-km sample group should read "-22.9\%", correcting the earlier "-17.0\%." The error was in the presentation of the table and does not affect the results or conclusions in the paper.

Published online: 11 January 2022

https://doi.org/10.1038/s43016-022-00459-1

(c) The Author(s), under exclusive licence to Springer Nature Limited 2022 